\title{
Nucleotide sequence and expression analysis of the Acetobacter xylinum phosphoglucomutase gene
}

\author{
Trygve Brautaset, Rune Standal, Espen Fjærvik and Svein Valla \\ Author for correspondence: Svein Valla. Tel: +4773598694 . Fax: +4773598705.
}

Unigen Center for Molecular Biology, University of

Trondheim, 7005

Trondheim, Norway
The Acetobacter xylinum gene (ce/B) encoding phosphoglucomutase (EC 5.4.2.2) has previously been cloned by complementation of cellulose-negative mutants. In the present report the nucleotide sequence of a $2.0 \mathrm{~kb}$ DNA fragment containing celB is described. Expression analysis using the bacteriophage T7 RNA polymerase promoter $\phi 10$ resulted in identification of a probable translational start codon of $C e / B$, and this conclusion was confirmed by $\mathrm{N}$-terminal amino acid sequencing of the recombinant protein. From the nucleotide sequence data it was deduced that celB encodes a protein with a calculated molecular mass of 59.6 kDa. A protein of similar size was visualized after in vitro transcription and translation, using the cloned $2.0 \mathrm{~kb}$ fragment as template. The results of an amino acid sequence comparison and a biochemical analysis indicated that the CelB protein is structurally and functionally related to the previously characterized human and rabbit phosphoglucomutases.

Keywords: Acetobacter xylinum, phosphoglucomutase, celB, cellulose

\section{INTRODUCTION}

Phosphoglucomutase catalyses the interconversion of $\mathrm{D}^{-}$ glucose 6-phosphate and D-glucose 1-phosphate, which represents a branch point in carbohydrate metabolism. Biochemical studies indicate that phosphoglucomutases from a variety of organisms convert glucose 1-phosphate much more efficiently than the corresponding 6-phosphate isomer (Lowry \& Passonneau, 1969; Ray \& Peck, 1972). Glucose 6-phosphate enters catabolic processes to yield energy and reducing power, whereas glucose 1phosphate is the precursor of sugar nucleotides that are used by the cells in the synthesis of various glucosecontaining polysaccharides. In a previous report we showed that phosphoglucomutase is essential for the formation of extracellular cellulose in Acetobacter xylinum, as mutants deficient in the corresponding gene are unable to produce cellulose (Fjærvik et al., 1991). A similar observation has also recently been reported for xanthan production in Xanthomonas campestris (Köplin et al., 1992). In Escherichia coli it has been shown that mutants deficient in phosphoglucomutase accumulate intracellular amylose when grown in the presence of maltose (Adhya \& Schwartz, 1971). The probable reason for this is that maltose metabolism results in the formation of glucose 1-

The GenBank accession number for the sequence data reported in this paper is L24077. phosphate which cannot be channelled into catabolism due to the phosphoglucomutase deficiency.

In the active form of phosphoglucomutase, a divalent metal ion is bound to the enzyme, and a serine residue at the catalytic site is phosphorylated (Ray \& Peck, 1972). This phosphate group is initially transferred to the substrate, and the serine residue is rephosphorylated concomitant with the release of either of the two phosphoglucose isomers (Rhyu et al., 1984). Recently the crystal structure of rabbit muscle phosphoglucomutase was described, and it was found that three loops are closely spaced in the active-site cleft (Dai et al., 1992). One loop contains the active-site serine, one is a metal-ionbinding loop, and the third is suggested to be involved in substrate-binding specificity.

Phosphomannomutase catalyses a reaction similar to the phosphoglucomutase reaction, and it has been reported that the phosphomannomutase (AlgC) of Pseudomonas aeruginosa contains both the active-site and the metalbinding-loop sequence motifs typical of phosphoglucomutases (Zielinsky et al., 1991). Interestingly, it has been shown that an enzyme from $X$. campestris can efficiently convert both phosphorylated glucose and mannose (Köplin et al., 1992).

In this paper the nucleotide sequencing and expression analysis of the $A$. xylinum phosphoglucomutase gene $c e l B$ 
Table 1. Bacterial strains and plasmids used in this study

\begin{tabular}{|c|c|}
\hline $\begin{array}{l}\text { Strain or } \\
\text { plasmid }\end{array}$ & Characteristics* and references \\
\hline \multicolumn{2}{|l|}{ E. coli } \\
\hline Hfr 3000 & $\operatorname{pgm}^{+}$(Adhya \& Schwartz, 1971) \\
\hline PGM1 & pgm derivative of Hfr3000 (Adhya \& Schwartz, 1971) \\
\hline \multicolumn{2}{|c|}{ Plasmids } \\
\hline pUC18,8.6B.dE & $\begin{array}{l}\text { pUC18 with a } 3.8 \mathrm{~kb} \text { EcoRI-BamHI insert; } c e l B^{+} \mathrm{Ap}^{\mathrm{r}} \\
\text { (Fiærvik et al., 1991) }\end{array}$ \\
\hline pUC128 & $\begin{array}{l}\text { Inducible lac promoter upstream of a polylinker; } A \mathrm{p}^{\mathrm{r}} \\
\text { (Keen } \text { et al., 1988) }\end{array}$ \\
\hline $\mathrm{p} T 7-4$ & $\begin{array}{l}\text { Bacteriophage } \mathrm{T} 7 \phi 10 \text { promoter upstream of a polylinker; } \\
\mathrm{Ap}^{\mathrm{r}} \text { (Tabor \& Richardson, } 1985 \text { ) }\end{array}$ \\
\hline pGP1-2 & $\begin{array}{l}\text { Thermo-inducible T7 RNA polymerase gene; } \mathrm{Km}^{\mathrm{r}} \text { (Tabor } \\
\text { \& Richardson, 1985) }\end{array}$ \\
\hline pT7-4S & $\begin{array}{l}\text { pT7-4 with an } S p b I \text { linker ligated into the polylinker } S m a \mathrm{I} \\
\text { site (this study) }\end{array}$ \\
\hline $\mathrm{pTB} 2 \mathrm{~A} / \mathrm{B}$ & $\begin{array}{l}\text { pUC128 with a } 2.0 \mathrm{~kb} S p b \mathrm{I} \text { insert from } \mathrm{pUC} 18,8.6 \mathrm{~B} . \mathrm{dE} \text { in } \\
\text { orientation } \mathrm{A} \text { and } \mathrm{B} \text {, respectively; } c e l \mathrm{~B}^{+} \text {(this study) }\end{array}$ \\
\hline $\mathrm{pTB} 3 \mathrm{~A} / \mathrm{B}$ & $\begin{array}{l}\text { pT7-4S with a } 2.0 \mathrm{~kb} S p h \mathrm{I} \text { insert from pUC18,8.6B.dE in } \\
\text { orientation } \mathrm{A} \text { and } \mathrm{B} \text {, respectively; } c e l \mathrm{~B}^{+} \text {(this study) }\end{array}$ \\
\hline pTB1 & pTB3A carrying nt 99 through 2058 from $c e l B$ (this study) \\
\hline рTB8 & pTB3A carrying nt 110 through 2058 from $c e l B$ (this study) \\
\hline pTB16 & pTB3A carrying nt 161 through 2058 from celB (this study) \\
\hline
\end{tabular}

*Ap ${ }^{\mathrm{r}}$, ampicillin resistance; $\mathrm{Km}^{\mathrm{r}}$, kanamycin resistance.

is reported, and some biological properties of the gene product are described.

\section{METHODS}

Bacterial strains, plasmids and growth media. Strains and plasmids used in this study are listed in Table 1. E. coli strains were, unless otherwise stated, grown at $37^{\circ} \mathrm{C}$ in L-broth or on L-agar (Valla t al., 1989) supplemented when appropriate with ampicillin $\left(100 \mu \mathrm{g} \mathrm{ml}^{-1}\right)$ or kanamycin $\left(50 \mu \mathrm{g} \mathrm{ml}^{-1}\right)$.

Preparation of DNA, molecular cloning, construction of deletion mutants, DNA sequencing, and computer analysis. Plasmid isolations, agarose gel electrophoresis, restriction endonuclease digestions, ligations and other routine DNA manipulations were performed according to standard protocols (Sambrook et al., 1989). Transformations were performed according to Chung et al. (1989). Unidirectional exonuclease degradations (Henikoff, 1987) of plasmids pTB3A and pTB3B were done with the Erase-a-base system (Promega). The resulting deletion derivatives were used for sequencing of both DNA strands by the dideoxy chain-termination method of Sanger et al. (1977). Homology searches with the deduced amino acid sequence of CelB were done using the BLAST network service at NCBI and the non-redundant DNA and protein sequence databases (Altschul et al., 1990).

In vivo expression studies of celB. The $2.0 \mathrm{~kb}$ celB-containing SpbI fragment from pUC18,8.6B.dE was cloned in both orientations into the corresponding site of the pUC128 polylinker, generating plasmids $\mathrm{pTB} 2 \mathrm{~A}$ and $\mathrm{pTB} 2 \mathrm{~B}$. These plasmids were transformed into $E$. coli PGM1 (deficient in phosphoglucomutase), and the phosphoglucomutase activities in the transformants were measured in extracts prepared from cells grown overnight. Expression analysis of the three pTB3A deletion derivatives p'B1, pTB8 and pTB16 were performed in strain PGM1 and PGM1 (pGP1-2). Cells were grown at $30^{\circ} \mathrm{C}$ to a density of approximately $5 \times 10^{8}$ cells $\mathrm{ml}^{-1}$, and T7 RNA polymerase-mediated transcription from the $\phi 10$ promoter was induced by heat as described by Tabor \& Richardson (1985). Preparation of cell-free extracts and measurements of phosphoglucomutase activities were performed as described previously (Fjærvik et al., 1991). Phosphomannomutase activity of CelB was assayed in extracts prepared from cells of PGM1(pTB2A) according to Sa'-Correia et al. (1987). Addition of mannose 6phosphate (1 mM final concentration) instead of $1 \mathrm{mM}$ mannose 1-phosphate was used as a control in the assay system. All enzyme assays were done at least twice. The results presented in Table 2 are representative values.

In vitro expression of celB. The $2.0 \mathrm{~kb} S p b \mathrm{I}$ fragment $(2 \mu \mathrm{g})$ containing $c e l B$ was electroeluted from an agarose gel and expressed in vitro using an E. coli $\mathrm{S} 30$ coupled transcriptiontranslation system (Promega). The translation product was labelled with $\left[{ }^{35} \mathrm{~S}\right]$ methionine $\quad\left(1200 \mathrm{Ci} / \mathrm{nmol}^{-1}\right.$; $44.4 \mathrm{TBq} \mathrm{nmol}^{-1}$ ) according to the manufacturer's instructions. Aliquots $(5-15 \mu \mathrm{l})$, together with ${ }^{14} \mathrm{C}$-labelled protein molecular mass markers, were subjected to SDS-PAGE $(8 \%, w / v$, acrylamide). The gel was fixed and soaked in Amplify (Amersham), dried, and exposed to X-ray film.

Determination of the $\mathbf{N}$-terminal amino acid sequence of CelB. Expression of $c e l B$ was induced by heat in PGM1 cells ( 1.01 culture) containing plasmids pTB1 and pGP1-2. Cells were harvested by centrifugation, washed twice in $60 \mathrm{ml}$ buffer $1\left(20 \mathrm{mM}\right.$ Tris/HCl, $1 \mathrm{mM} \mathrm{Na} \mathrm{NaDTA}_{2}$ E $1 \mathrm{mM}$ dithiothreitol, $10 \%, \mathrm{v} / \mathrm{v}$, glycerol, and $100 \mathrm{mM} \mathrm{KCl}, \mathrm{pH} \mathrm{7.4}$ ) and resuspended 


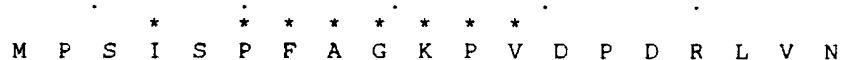
TTGTAGAATATGCACTTTTTCATATCGCATTTCGGGAGCAGTCAATGCCCAGCATAAGCCCATTTGCCGGCAAGCCGGTCGATCCGGACCGTCTTGTCAA $\begin{array}{lllllllllllllllllllllllllllllllllll} & D & A & L & L & D & \dot{A} & Y & Y & T^{*} & R & K & P & D & P & A & \dot{I} & A & T & Q^{*} & R & V & A & F & G & T & \dot{S} & G & H & R & G & S & S^{*}\end{array}$ TATCGACGCCCTGCTTGACGCCTATTATACCCGCAAGCCTGACCCCGCCATTGCAACGCAGCGCGTGGCGTTTGGCACGTCGGGGCATCGTGGTTCCTCG

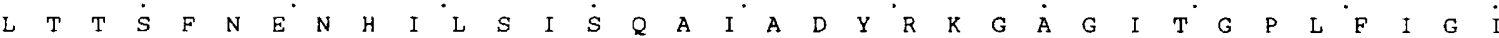
CTGACCACCAGCTTCAATGAAAACCACATCCTGTCGATCAGCCAGGCGATTGCCGATTACCGCAAGGGCGCGGGCATCACCGGGCCGCTGTTCATCGGCA

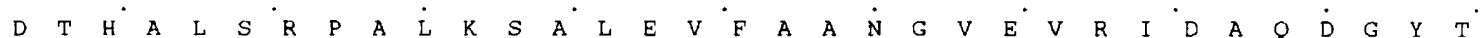
TTGACACCCATGCGCTGTCGCGGCCGGCGTTGAAATCCGCGCTGGAAGTGTTCGCGGCCAATGGCGTGGAAGTCCGTATCGACGCGCAGGACGGCTATAC $P$
CCCCACGCCGGTCATCTCGCACGCGATCCTGACCTATAACCGTGACCGCAGCAGTTACCTGGCCGATGGCGTGGTGATCACCCCCGTCGCATAACCCGCCG

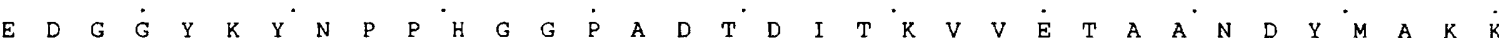
GAAGATGGCGGCTACAAGTACAATCCCCCCCATGGCGGCCCGGCGGATACCGACATCACCAAGGTGGTGGAAACTGCGGCCAACGACTACATGGCCAAAA

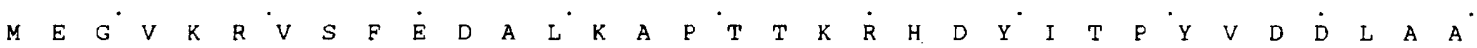
AGATGGAAGGCGTGAAGCGCGTCAGTTTCGAGGACGCGCTGAAGGCCCCCACCACGAAGCGCCATGACTACATCACGCCGTATGTGGATGACCTGGCCGC

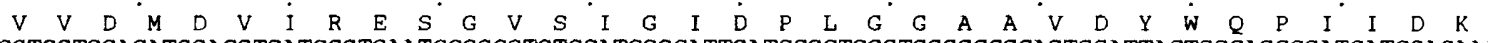
CGTGGTGGACATGGACGTGATCCGTGAATCCGGCGTGTCCATCGGCATTGATCCGCTGGGTGGGGCCGCAGTGGATTACTGGCAGCCGATCATCGACAAA

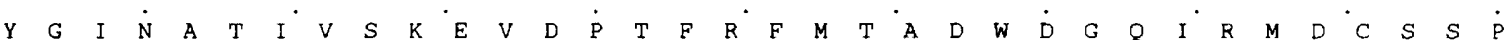
TACGGCATCAACGCCACGATCGTCAGCAAGGAAGTGGACCCGACCTTCCGCTTCATGACCGCTGACTGGGACGGGCAGATCCGCATGGACTGTTCCTCCC $\begin{array}{llllllllllllllllllllllllllllllllll}Y & A & M^{*} & A & R & L & V & G & M & \dot{K} & D & K & F^{*} & D & I & A & F & A & N & \dot{D} & T & D & A & D & R & H & G & I & V & \dot{S} & G & K & Y^{\circ}\end{array}$ CCTACGCCATGGCGCGCCTTGTCGGGATGAAGGACAAATTCGACA TCGCCTTCGCCAATGATACCGATGCCGACCGCCATGGCATCGTATCGGGCAAGTA

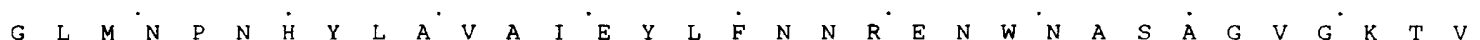
CGGGCTTATGAACCCCAACCACTATCTGGCTGTCGCGATTGAATACCTGTTCAACAATCGCGAAAACTGGAATGCCAGCGCGGGCGTGGGCAAGACGGTG

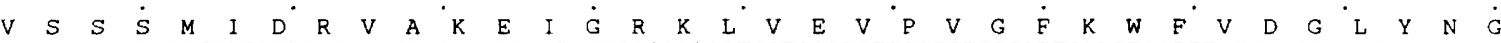
GTCAGCAGCAGCATGATCGACCGCGTGGCCAAGGAAATCGGCCGCAAGCTGGTGGAAGTGCCGGTCGGGTTCAAGTGGTTTGTCGATGGGCTGTACAACG $T$ L L G GCACGCTGGGCTTTGGCGGTGAAGAAAGCGCGGGCGCGTCCTTCCTGCGCCGTGCCGGCACGGTGTGGAGCACGGACAAGGACGGCATCATCCTTGGCCT

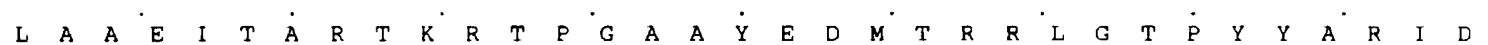
GCTGGCAGCCGAGATCACGGCCCGCACCAAGCGCACCCCCGGTGCGGCGTATGAGGACATGACCAGACGCCTGGGCACGCCGTACTACGCACGGATCGAC

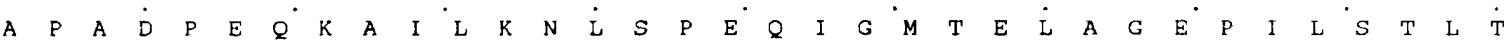
GCCCCGGCCGACCCGGAACAGAAGGCCATCCTGAAAAACCTTTCGCCCGAGCAGATCGGCATGACCGAACTGGCGGGTGAGCCGATCCTCAGCACGCTGA $\begin{array}{lllllllllllllllllllllllllllllllllllllll}N & A & P^{\circ} & G & N & G & A & A & I & \dot{G} & G & L & K & V & S & A & K & D & G & \dot{W} & F & A & A & R & P & S & G & T & E & \dot{N} & V & Y & K\end{array}$ CCAACGCACCGGGCAACGGGGCGGCCATTGGCGGGCTGAAGGTTTCGGCAAAGGACGGCTGGTTTGCCGCCCGTCCGTCGGGTACGGAAAACGTCTATAA

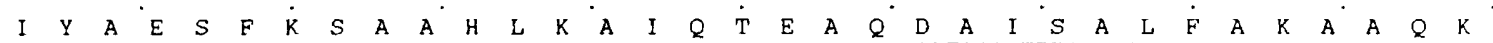
GATCTATGCCGAAAGCTTCAAGAGTGCTGCGCACCTCAAGGCCATCCAGACCGAGGCACAGGATGCGATTTCCGCCCTGTTCGCCAAGGCTGCCCAGAAA N A G AACGCTGGCTGATCTGTAATATGATTCCATGTCCCGGTAGCGGGACATGGGCTGGTGCCGTCAGGCCGTCATGGGCAGGCGGCATTTTTTGGATTATTGC TGAAAAATCAGAAGAAAGTTTTTAGTGAAGCTTTTTTCAAAAAGCTTTAAAGAACGCCGGCT'TTTTGAAAAAAGGCGGCACCCAAAAACTTTTTATTATCT ATCAATCAA T'TAAACGAAA TAATCCCTTATGGCGATGGGGGAATGACCGGCGGCATGC

Fig. 1. Nucleotide sequence of the cloned $2.0 \mathrm{~kb} \mathrm{Sphl}$ fragment and the deduced amino acid sequence of CelB. The start and stop codons and a putative Shine-Dalgarno sequence are underlined and double-underlined, respectively. Residues identified by $\mathrm{N}$-terminal amino acid sequencing are marked with asterisks.

in $8 \mathrm{ml}$ buffer 2 (buffer 1 supplemented with $50 \mathrm{mg}$ phenylmethylsulfonyl fluoride $\mathrm{ml}^{-1}$ ). All remaining operations were done at $0-4{ }^{\circ} \mathrm{C}$. Cells were disrupted by sonication and the cell debris was removed by centrifugation $(12000 \mathrm{~g}, 1 \mathrm{~h})$. Proteins in the supernatant were precipitated with $0.38 \%$ polyethylenimine (Sigma) and collected by centrifugation $(12000 \mathrm{~g}$, $10 \mathrm{~min}$ ). The pellet was resuspended in $5 \mathrm{ml} 10 \mathrm{mM}$ sodium phosphate, $\mathrm{pH} 5.8$ (buffer 3 ), and the suspension was dialysed against $3 \mathrm{l}$ of this buffer overnight.

After centrifugation $(12000 \mathrm{~g}, 10 \mathrm{~min})$, the protein extract was loaded on a Sepharose Q column (Bio-Rad Poly Prep., $10 \mathrm{ml}$ bead volume), previously equilibrated with buffer 3 . Proteins were eluted with a linear gradient of $0 \cdot 1-1 \cdot 0 \mathrm{M}$ sodium

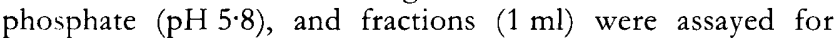
phosphoglucomutase activity. Two of the active fractions were pooled and dialysed against buffer 3 overnight. The protein extract was concentrated 20 -fold by freeze-drying, and then subjected to SDS-PAGE, as described above. The proteins were transferred to an Immobilon polyvinylidene difluoride membrane (Millipore) by Western blotting, using a buffer containing $25 \mathrm{mM}$ Tris-base, $0 \cdot 2 \mathrm{M}$ glycine, and $20 \%$ (v/v) methanol. After staining the membrane with Coomassie Brilliant Blue R250 , a band with the expected molecular mass was excised and used directly for amino acid sequence analysis in a model $477 \mathrm{~A}$ protein sequencer from Applied Biosystems.

Measurements of intracellular amylose. The analyses were performed by a modification of the method described by Adhya \& Schwartz (1971). Cells were grown overnight in $100 \mathrm{ml} \mathrm{M} 9$ medium (Sambrook t al., 1989) supplemented with glucose or maltose $(0 \cdot 2 \%)$. After harvesting by centrifugation, the cells were washed in $40 \mathrm{mM}$ imidazole- $\mathrm{HCl}(\mathrm{pH} \mathrm{7.4)}$ and resuspended in $5 \mathrm{ml}$ of the same buffer. The cells were disrupted by 
sonication, and cell debris was removed by centrifugation $(10000 \mathrm{~g}, 1 \mathrm{~min})$. Aliquots $(1 \mathrm{ml})$ of the supernatants were used directly for amylose analysis by adding $0.1 \mathrm{ml}$ staining solution $\left(0.1 \% \mathrm{I}_{2}, 1.0 \% \mathrm{KI}\right)$. The presence of amylose was detected as appearance of a deep blue colour. The experiments were done three times. Quantitative measurements were done in one of these experiments by measuring the absorbance at $610 \mathrm{~nm}$. Solutions containing pure amylose and the staining mixture were used as standards.

\section{RESULTS AND DISCUSSION}

\section{Localization of celB within the cloned fragment}

Plasmid pUC18,8.6B.dE was previously shown to express the A. xylinum celB gene in E. coli (Fjærvik et al., 1991). Deletion derivatives of the $3.8 \mathrm{~kb}$ DNA insert in this plasmid were constructed, and enzyme assays of PGM1 cells containing such plasmid derivatives indicated that a

Table 2. Expression analysis of celB using the T7 RNA polymerase promoter system

The numbers represent nmol substrate transformed $\mathrm{min}^{-1}$ (mg total protein $)^{-1}$. PGM1 was used as host in the experiments, and all measurements were performed under induced conditions.

\begin{tabular}{|ccc|}
\hline Plasmid & \multicolumn{2}{c|}{$\begin{array}{c}\text { Phosphoglucomutase } \\
\text { activity }\end{array}$} \\
\cline { 2 - 3 } & + pGP1-2 & - pGP1-2 \\
& 18000 & 700 \\
p'TB1 & 4400 & 400 \\
p'TB16 & 20 & 0 \\
p'TB8 & & \\
\hline
\end{tabular}

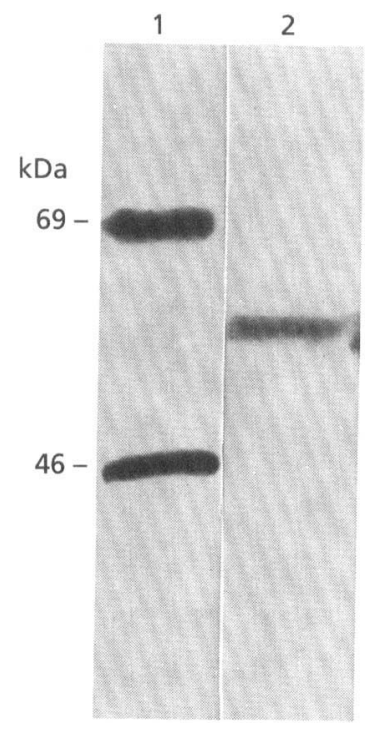

Fig. 2. Autoradiogram of an SDS-PAGE gel showing the in vitro-translated and $\left.{ }^{35} S\right]$ methionine-labelled celB gene product. Lanes: 1, protein molecular mass standards (sizes in $\mathrm{kDa}$ in left margin); 2, CelB.
$2.0 \mathrm{~kb} S p h \mathrm{I}$ fragment encoded the phosphoglucomutase activity. This was confirmed by enzyme assays of PGM1 cells containing pTB2A and pTB2B, which demonstrated that $c e l B$ was expressed from both plasmids (data not shown). pTB2A expressed a 10-fold higher phosphoglucomutase activity than $\mathrm{pTB} 2 \mathrm{~B}$, indicating that the orientation of the $S p h I$ fragment in pTB2A allowed $c e l B$ to be transcribed from the lac promoter in the vector.

\section{Identification of the celB coding sequence}

The molecular masses of phosphoglucomutases from several organisms have been determined; they range from 60 to $65 \mathrm{kDa}$ (Ray \& Peck, 1972). This indicates that the coding sequences for the corresponding genes are between 1.6 and $1.8 \mathrm{~kb}$, and we therefore decided to sequence the entire $2.0 \mathrm{~kb} S p h \mathrm{I}$ fragment. Prior to sequencing, the fragment was subcloned in both orientations into the corresponding site in the plasmid expression vector $\mathrm{pT} 7-4 \mathrm{~S}$, generating plasmids $\mathrm{p}$ TB3A and $\mathrm{p}$ TB3B. The orientation of the SphI fragment relative to the lac $/ \phi 10$ promoters was found to be the same in $\mathrm{pTB} 2 \mathrm{~A}$ and $\mathrm{pTB} 3 \mathrm{~A}$. This indicates that the $5^{\prime}$ end of $c e l B$ in pTB3A is localized proximal to the $\phi 10$ promoter. The nucleotide sequence of the $S p h \mathrm{I}$ fragment was determined, and the sequence data revealed an open reading frame (ORF1) starting with ATG at nucleotides (nt) 145-147 and terminating with TGA at nt 1810-1812 (Fig. 1).

Inserts cloned in the polylinker of pT7-4S can be transcribed from the $\phi 10$ promoter, which is specifically recognized by the bacteriophage T7 RNA polymerase (encoded by pGP1-2). In order to identify the biologically active start codon we performed an expression analysis of three deletion derivatives of pTB3A (pTB1, pTB8 and pTB16). The results of this analysis (Table 2) demonstrated that $\mathrm{p} T \mathrm{~B} 1$ and $\mathrm{p} T \mathrm{~B} 16$ expressed $c e l \mathrm{~B}$, and that the expression was strongly stimulated by T7 RNA polymerase. Very little or no activity was detected in cells containing pTB8. There is no Shine-Dalgarno (SD) sequence in the $\phi 10$-polylinker region in p T7-4S, and the results thus indicated the presence of a biologically active SD sequence in the inserts of pTB1 and pTB16. A putative SD sequence (GGAG) was identified upstream of ORF1 at nt 135-138 (Fig. 1). These experiments thus indicated that the ATG at nt 145-147 in ORF1 represents the biologically active start codon of $c e l B$. ORF1 corresponds to a polypeptide consisting of 555 amino acids and the calculated molecular mass of the protein is $59 \cdot 6 \mathrm{kDa}$. This is consistent with the results of an in vitro expression analysis of $c e l B$, which demonstrated that the $2.0 \mathrm{~kb} S p h \mathrm{I}$ fragment directed the synthesis of a protein with a molecular mass of approximately $60 \mathrm{kDa}$ (Fig. 2).

The purified CelB protein obtained by in vivo expression in $E$. coli was sequenced at the amino-terminal end; in eight of the eleven first sequencing steps the amino acids could be definitely identified. All these amino acids are consistent with the deduced sequence of ORF1 (Fig. 1), with the exception that they were all assigned a position one residue number lower than predicted from the nucleotide sequence. The results thus indicated that the initiating 


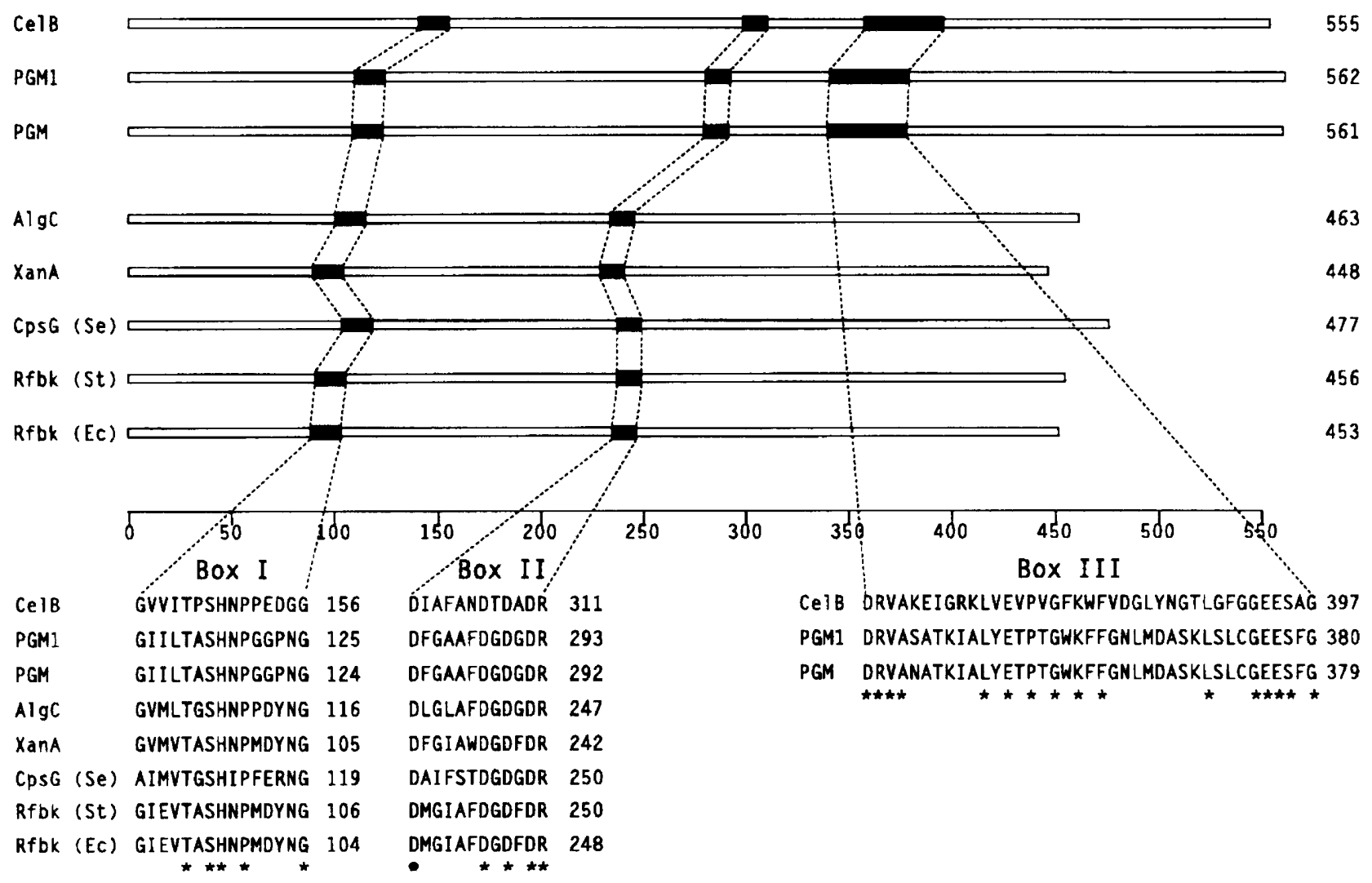

Fig. 3. Comparison between the deduced amino acid sequences of CelB and other related enzymes. Top: Schematic representation of individual amino acid sequences depicting the localization of conserved regions (boxes I, II, and III). The numbers to the right refer to the number of amino acid residues in the different proteins. Bottom: Alignment of boxes I, II and III. The number after each sequence is the number of the last residue in each motif in its corresponding sequence. The abbreviations used for the enzymes, and the sources of the sequences, are as follows: CelB, $A$. xylinum phosphoglucomutase (this study); PGM1, human phosphoglucomutase (Whitehouse et al., 1992); PGM, rabbit muscle phosphoglucomutase (Ray et al., 1983); AlgC, P. aeruginosa phosphomannomutase (Zielinski et al., 1991); XanA, X. campestris phosphogluco-/mannomutase (Köplin et al., 1992); CpsG (Se), Salmonella enterica phosphomannomutase (Stevenson et al., 1991); RfbK (St), Salmonella typhimurium phosphomannomutase (Jiang et al., 1991); RfbK (EC), E. coli phosphomannomutase (Marolda \& Valvano, 1993).

formylmethionine is removed from CelB when expressed in E. coli.

\section{Effect of CelB on intracellular amylose synthesis in $E$. coli}

The in vivo effect of CelB on intracellular amylose synthesis in E. coli was analysed by growing cells in the presence of glucose or maltose as carbon sources. In agreement with previous observations (Adhya \& Schwartz, 1971), it was found that PGM1 accumulated amylose $[0.14 \mathrm{mg}$ (mg dry $\mathrm{wt})^{-1}$ ] when grown on maltose, while no amylose was detected when glucose was used as carbon source. PGM1 cells containing a celB-expressing plasmid (pUC18,8.6.dE) did not accumulate amylose when grown under these conditions, and the same was true for the isogenic wildtype strain of PGM1 (Hfr3000). These experiments thus indicated that CelB could substitute for the E. coli enzyme in transforming the glucose 1-phosphate formed in the cells during growth on maltose to glucose 6-phosphate. In the biosynthesis of cellulose in A. xylinum, CelB is essential for the formation of glucose 1-phosphate. The ability of CelB to catalyse both directions of the glucose phosphate isomerization in vivo is thus demonstrated.

\section{Structural and biochemical comparisons between CelB and other related enzymes}

The amino acid sequence of CelB was compared with the primary structures of previously reported phosphoglucomutases and phosphomannomutases (Fig. 3). The polypeptide chains of CelB and the human and rabbit phosphoglucomutases are about 100 amino acids longer than the phosphomannomutases. Although there was no overall sequence similarity, the analysis revealed two highly conserved regions (Box I and Box II). The Box I motif contains the catalytic site of the enzymes, which was originally identified in rabbit muscle phosphoglucomutase (Ray \& Peck, 1972). In rabbit muscle phosphoglucomutase the Box II motif contains a metal-ion-binding loop (DGDGD) which is exposed in the active-site cavity (Dai et al., 1992). 
The third region of homology (Box III, not reported previously) was found only in CelB and the two eukaryotic (human and rabbit) phosphoglucomutases. This motif consists of 39 amino acids, and 38 of these are the same in the rabbit and human enzymes, while there are 16 matches $(41 \%)$ between CelB and the two eukaryotic sequences. In the rabbit muscle enzyme three amino acids (ESF) at the end of this motif are exposed in the active-site cavity, and it is suggested that they interact with the substrate glucose ring (Dai et al., 1992).

Among all the phosphoglucomutases previously reported, the $X$. campestris enzyme $(\mathrm{Xan} A)$ is unique in that it can efficiently use both phosphorylated mannose and glucose as substrates. We have analysed CelB with respect to this property, and the results of these experiments showed that the activity with mannose 1-phosphate was less than $0.2 \%$ of the activity with glucose 1 -phosphate. CelB is in this respect similar to the rabbit and human phosphoglucomutases, which have been reported to be specific for glucose phosphates (Lowry \& Passonneau, 1969). The presence of the Box III motif only in these three enzymes suggests the possibility that this motif is responsible for their phosphoglucose specificity, and that the enzymes lacking this motif may have a broader substrate specificity. Except for XanA, the ability to convert phosphoglucose has to our knowledge not been determined for the phosphomannomutases included in this comparison.

\section{ACKNOWLEDGEMENTS}

We thank Dr Knut Sletten for his help with the amino acid sequencing.

\section{REFERENCES}

Adhya, S. \& Schwartz, M. (1971). Phosphoglucose mutants of Eschericbia coli $\mathrm{K}-12$. J Bacteriol 108, 621-626.

Altschul, S. F., Gish, W., Miller, W., Myers, E. W. \& Lipman, D. J. (1990). Basic local alignment search tool. J Mol Biol 215, 403-410.

Chung, C. T., Niemela, S. L. \& Miller, R. H. (1989). One-step preparation of competent Eschericbia coli: transformation and storage of bacterial cells in the same solution. Proc Natl Acad Sci US A 86, 2172-2175.

Dai, J.-B., Liu, Y., Ray, W. J. \& Konno, M. (1992). The crystal structure of muscle phosphoglucomutase refined at $2 \cdot 7$-angstrom resolution. J Biol Chem 267, 6322-6337.

Fjærvik, E., Frydenlund, K., Valla, S., Huggirat, Y. \& Benziman, M. (1991). Complementation of cellulose-negative mutants of Acetobacter xylinum by the cloned structural gene for phosphoglucomutase. FEMS Microbiol Lett 77, 325-330.

Henikoff, S. (1987). Unidirectional digestion with exonuclease III in DNA sequence analysis. Methods Enzymol 155, 156-165.

Jiang, X. M., Neal, B., Santiago, F., Lee, S. J., Romana, L. K. \& Reeves, P. R. (1991). Structure and sequence of the $r f b$ (O antigen) gene cluster of Salmonella serovar typhimurium (strain LT2). Mol Microbiol 5, 695-713.

Keen, N. T., Tamaki, S., Kobayashi, D. \& Trollinger, D. (1988).
Improved broad-host-range plasmids for DNA cloning in Gramnegative bacteria. Gene 70, 191-197.

Köplin, R., Arnold, B., Hötte, B., Simon, R., Wang, G. \& Pühler, A. (1992). Genetics of xanthan production in Xanthomonas campestris: the $x a n A$ and $x a n B$ genes are involved in UDP-glucose and GDP. mannose biosynthesis. J Bacteriol 174, 191-199.

Lowry, O. H. \& Passonneau, J. W. (1969). Phosphoglucomutase kinetics with the phosphates of fructose, glucose, mannose, ribose, and galactose. $J$ Biol Chem 244, 910-916.

Marolda, C. L. \& Valvano, M. A. (1993). Identification, expression, and DNA sequence of the GDP-mannose biosynthesis genes encoded by the O7 rfb gene cluster of strain vW187 (Escherichia coli O7:K1). J Bacteriol 175, 148-158.

Ray, W. J., Jr \& Peck, E. J., Jr (1972). Phosphomutases. In The Enzymes, 3rd edn, vol. 6, pp. 407-458. Edited by P. D. Boyer. New York: Academic Press.

Ray, W. J., Jr, Hermodson, M. A., Puvathingal, J. M. \& Mahoney, W. C. (1983). The complete amino acid sequence of rabbit muscle phosphoglucomutase. J Biol Chem 258, 9166-9174.

Rhyu, G. I., Ray, W. J., Jr \& Markley, J. L. (1984). Enzyme-bound intermediates in the conversion of glucose-1-phosphate to glucose6-phosphate by phosphoglucomutase. Phosphorus NMR studies. Biocbemistry 23, 252-260.

Sa'-Correia, I., Darzins, A., Wang, S. K., Berry, A. \& Chakrabarty, A. M. (1987). Alginate biosynthetic enzymes in mucoid and nonmucoid Pseudomonas aeruginosa: overproduction of phosphomannose isomerase, phosphomannomutase, and GDP-mannose pyrophosphorylase by overexpression of the phosphomannose isomerase (pmi) gene. $J$ Bacteriol 169, 3224-3231.

Sambrook, J., Fritsch, E. F. \& Maniatis, T. (1989). Molecular Cloning: a Laboratory Manual, 2nd edn. Cold Spring Harbor, NY: Cold Spring Harbor Laboratory.

Sanger, F., Nicklen, S. \& Coulson, A. R. (1977). DNA sequencing with chain-terminating inhibitors. Proc Natl Acad Sci USA 74, 5463-5467.

Stevenson, G., Lee, S. J., Romana, L. K. \& Reeves, P. R. (1991). The cps gene cluster of Salmonella strain LT2 includes a second mannose pathway: sequence of two genes and relationship to genes in the $r f b$ gene cluster. Mol \& Gen Genet 227, 173-180.

Tabor, S. \& Richardson, C. C. (1985). A bacteriophage T7 RNA polymerase/promoter system for controlled exclusive expression of specific genes. Proc Natl Acad Sci US A 82, 1074-1078.

Valla, S., Coucheron, D. H., Fjærvik, E., Kjosbakken, J., Weinhouse, H., Ross, P., Amikan, D. \& Benziman, M. (1989). Cloning of a gene involved in cellulose biosynthesis in Acetobacter xylinum: complementation of cellulose-negative mutants by the UDPG pyrophosphorylase structural gene. Mol \& Gen Genet 217, 26-30.

Whitehouse, D. B., Putt, W., Lovegrove, J. U., Morrison, K., Hollyoake, M., Fox, M. F., Hopkinson, D. A. \& Edwards, Y. H. (1992). Phosphoglucomutase 1 : complete human and rabbit mRNA sequences and direct mapping of this highly polymorphic marker on human chromosome 1. Proc Natl Acad Sci USA 89, 411-415.

Zielinski, N. A., Chakrabarty, A. M. \& Berry, A. (1991). Characterization and regulation of the Pseudomonas aeruginosa algC gene encoding phosphomannomutase. J Biol Chem 266, 9754-9763.

Received 27 September 1993; revised 11 November 1993; accepted 29 November 1993. 